\title{
The Promise and Potential of Online Dispute Resolution in Japan
}

\author{
Hiroki Habuka \& Colin Rule
}

\begin{abstract}
Information technology has dramatically changed the way consumers and businesses transact around the world. Many consumer goods (such as videos, music and software) are purchased online through the Internet instead of through physical stores. Businesses have similarly migrated many of their commercial transactions online, including proposals, due diligence, negotiation and signing. However, most dispute resolution processes have not yet made a similar move; they occur face-toface, even when the dispute arose online. This has led to a new type of dispute resolution, called ODR (or Online Dispute Resolution). ODR is the use of technology to resolve disputes, and it is being promoted in many countries around the world as a model for civil justice in an online age. North America and the European Union $(E U)$ have aggressively promoted $O D R$, and there are many $O D R$ projects currently underway. As one of the leading online economies in the world, Japan is facing many of the same challenges as the rest of the world in providing fast and fair resolutions to online consumers. But to date, ODR has not gotten much traction in Japan. Recently, the Japanese Consumer Network published a report about ODR for cross-border e-commerce transactions and encouraged the government to establish a working group for implementation of ODR. However, discussion by multiple stakeholders towards practical implementation of ODR has not yet started in earnest. This article aims to focus the discussion about how to implement ODR in Japan, providing information about the latest developments in global ODR frameworks and envisioning the challenges ODR faces in the Japanese market.
\end{abstract}

Keywords: Online Dispute Resolution, ODR, ADR, e-Commerce.

\section{What Is ODR?}

The field of ODR focuses on the use of information and communications technologies to prevent, manage and resolve disputes. ODR is an outgrowth from the Alternative Dispute Resolution (ADR) field, which is focused on face-to-face dis-

* Hiroki Habuka is a Deputy Director of Information Economy Division, Commerce and Information Policy Bureau, of Ministry of Economy, Trade and Industry of Japan (METI). He graduated from University of Tokyo Law School (J.D.) and Stanford Law School (LL.M.). Colin Rule is Vice President, Online Dispute Resolution, Tyler Technologies. He served as Director of Online Dispute Resolution at eBay and PayPal, and co-founded Modria.com, an ODR provider that was sold to Tyler Technologies in 2017. 
pute resolution practice. ODR marries the tools, techniques, ethical standards and best practices of the ADR field, honed over decades, with cutting-edge technology. The objective of ODR is to expand access to justice and provide fast and fair resolutions to as many disputants as possible using the power and reach of information technology.

ODR first emerged in the late 1990s as a means of resolving disagreements regarding purchases conducted over the Internet. Early ODR pioneers like the global eBay marketplace and the Internet Corporation for Assigned Names and Numbers demonstrated how high volumes of disputes could be efficiently resolved even in cross-jurisdictional transactions. Since that time, ODR has grown into a global movement backed by many dozens of providers around the world, undergirded by a strong academic and theoretic foundation. The National Center for Technology and Dispute Resolution (odr.info) serves as a hub for this global movement, supporting a global network of ODR Fellows and an Annual Conference that has met more than 16 times on five continents.

\section{The Importance of ODR to e-Commerce}

ODR is essential to e-commerce because large online marketplaces and merchants (companies like eBay, Amazon and Alibaba) must provide their users with fast and fair redress processes so as to bolster user trust. Consumers can now pick up their laptop or phone and, with just a few swipes of their finger, purchase an item or service from any seller around the globe. However, if consumers are worried that they will not be able to get quick resolutions to problems they encounter with regard to these purchases, they will be less likely to buy. Consumers may be particularly concerned about getting redress in cross-border transactions, because the redress processes they depend upon for domestic face-to-face purchases are not effective if the transaction partner is in another country or even on another continent. ODR is particularly well-suited for low-value, high-volume, cross-border transactions, because ODR is jurisdiction independent, meaning it can provide redress across borders without having to reconcile conflicting legal regimes.

After more than 20 years of analysis and research, governments around the world are now promoting ODR as a means of expanding access to justice for their citizens. A consensus has emerged among regulators, consumer advocates and marketplace administrators that ODR is the best option for resolving cross-border consumer issues. As a result, there has been a wave of laws and regulations encouraging (and in some cases requiring) the expanded availability of ODR. But these initiatives have not developed at the same rate in every region. Some countries are far ahead in deploying ODR, while other countries are behind. But all countries now know that the future of commerce is online. Any economy that wants to be a leader in global e-commerce must have a robust infrastructure in place to reassure consumers, both domestic and international, that they will be able to get redress should a problem arise. That is why ODR must be a priority. 


\section{The Global Trend Towards ODR}

Global e-commerce is growing at a rate of $20 \%$ per year. There were more than 50 billion e-commerce purchases globally in 2017, which means that in 2018 there will be 60 billion or more. Studies have shown that approximately $1 \%$ to $3 \%$ of ecommerce transactions generate a dispute, so that means there were about 1 billion global e-commerce disputes in 2017, and that number will continue to grow at the same rate as e-commerce grows.

Large e-commerce marketplaces have responded to this growth in disputes by building their own redress processes. In 2004, eBay launched the Resolution Center, which has since resolved hundreds of millions of disputes. Similarly, the Chinese e-commerce giant Alibaba also has an ODR-based resolution process that processes an even greater volume of cases. Even sharing economy companies like Airbnb and Upwork have integrated Resolution Centers into their marketplaces to provide quick and efficient resolutions to any problems that arise. And not all redress processes look the same: the TaoBao online marketplace in China has resolved millions of disputes through a crowdsourced resolution process which utilizes online juries.

But relying on each individual marketplace to build effective redress is not enough. Many e-commerce transactions take place outside of large marketplaces, and individual merchants do not have the resources to build robust ODR systems. National consumer protection authorities have dealt with consumer complaints regarding cross-border e-commerce purchases since the late 1990s, but they had no effective way to pursue these cases to resolution. As a result, momentum has built behind international proposals to deploy ODR to assist consumers in these kinds of cases. International organizations have promoted ODR as a solution to access to justice challenges since 2002. UNCITRAL, the United Nations organization in charge of harmonizing global laws, convened a working group devoted to ODR with more than 66 participating national delegations, and the group issued its final recommendations in 2016.

In Europe, the number of private and public ODR start-ups has grown steadily. Certain countries have led the way as early adopters (e.g., England, The Netherlands), but now the more conservative governments on the continent are following suit. ${ }^{1}$ In 2015 , the EU adopted a new regulation requiring all merchants in EU member states to notify their consumers about the availability of ODR, and the EU launched its own ODR filing form to collect buyer complaints and distribute them to regionally appropriate ODR service providers. An excellent example of the expansion of dispute resolution in Europe is the Directive 2008/52/CE de le Parlement Européen et de Conseil de 21 Marz, 2008, ${ }^{2}$ which made mediation mandatory in EU member states in certain cases such as torts and contract disputes,

1 G. Ross \& M. Poblet. 'ODR in Europe', in M. S. A. Wahab, E. Katsh, \& D. Rainey (Eds.), Online Dispute Resolution: Theory and Practice, The Hague, Eleven International Publishing, 2013.

2 European Parliament \& The European Union Council. (2008). Directiva 2008/52/CE do Parlamento Europeu e do Conselha - May 21st, 2008 relates certain aspects of the civil and commercial mediation. Estrasburgo, Jornal Oficial da União Europeia. 
where the parties were from different countries. Now, the International Standards Organization is evaluating a proposal to make ODR a de facto standard for all international e-commerce transactions.

The momentum behind ODR appears to be growing around the world. Those who have seriously considered the problem of access to justice, especially for high-volume/low-value cross-jurisdictional disputes, have come to the conclusion that ODR is the best option for the future. Judges, Bar Association presidents, regulators, general counsels and legal aid attorneys are all confronting shrinking budgets, growing numbers of self-represented litigants and changing expectations among the constituencies they are trying to serve. The track record that ODR has already achieved in a wide variety of global applications is encouraging them to think seriously about how ODR can work in their home geographies. ${ }^{3}$ With all of this momentum, it is clear that ODR's time has truly arrived.

\section{Why Does Japan Need ODR?}

But while ODR has gained immense traction in geographies like China, North America and Europe, ${ }^{4}$ the development of ODR in other regions of the world has been more inconsistent. One example of a leading e-commerce region that has lagged behind in the deployment of ODR is Japan. An international survey of the growth of ODR by Melissa Conley Tyler in 2005 indicated that Japan's use of ODR lagged behind initiatives in other geographies, ${ }^{5}$ but the potential of ODR approaches in tackling the challenges being experienced in Japan was clear even before ODR experiments began in earnest. The delay in Japan's adoption of ODR approaches might have even been a benefit in retrospect, as other geographies have since tested and refined ODR tools, ensuring that Japanese businesses and regulators can now leverage other countries' best practices in designing their own initiatives. The geographies that were most successful in implementing ODR were those that coordinated its launch between many stakeholders, including governmental organizations, foundations, chambers, private start-ups or individual enthusiasts. Now that the global consensus around ODR's value is clear, Japan can begin to convene a similar set of stakeholders.

The Japanese e-commerce market is enormous. Japan has the fourth largest Business-to-Consumer (B2C) e-commerce market in the world, following China, the United States and the United Kingdom. ${ }^{6}$ In 2017, B2C e-commerce transac-

3 E. Katsh \& C. Rule, 'What we know and need to know about Online Dispute Resolution', South Carolina Law Review, Vol. 67, No. 329, pp. 5-6.

4 "As of July 2004, at least 115 ODR services had been launched worldwide, settling more than 1.5 million disputes. ODR services offer examples of using technology to resolve everything from eBay disputes to commercial litigation; from family disputes to the Sri Lankan peace process. There are now ODR services in all regions." (M. Conley Tyler, 115 and Counting: The State of ODR 2004. Proceedings of the Third Annual Forum on Online Dispute Resolution, University of Melbourne, 2004, p. 1).

$5 \quad$ M. Conley Tyler, 2004, p. 2.

6 Information Economy Division, METI, '2017 Establishing a Base for Data-Driven Society in Japan (Market Research for E-Commerce)’, METI Report 2017, 2018, p. 92. 
tions of goods amounted to $\$ 95.3$ billion, which comprises $5.79 \%$ of all the B2C transactions in the country. ${ }^{7}$

Consumer-to-Consumer e-commerce (or C2C), sometimes referred to as the 'sharing economy', is also on the rise. C2C e-commerce transaction volumes in 2017, including both direct sales and online auctions, amounted to JPY 840 billion ( $\$ 7.64$ billion), which is more than $8 \%$ of overall B2C transaction volumes. ${ }^{8}$ Besides the sales of tangible goods, there are also various other successful C2C markets such as renting rooms, hiring transportation or other services. The total market size of these $\mathrm{C} 2 \mathrm{C}$ e-commerce transactions in Japan is reported to have reached more than JPY 1,000 billion ( $\$ 9.1$ billion). ${ }^{9}$

A unique aspect of Japan's e-commerce marketplace is the large volume of exports compared with imports. Purchases from Japanese businesses by US consumers totalled JPY 713 billion ( $\$ 6.48$ billion) in 2017, while purchases by Japanese consumers from US business was only JPY 233 billion ( $\$ 2.12$ billion). Likewise, e-commerce sales from Japan to China totalled JPY 1.30 trillion ( $\$ 11.8$ billion), while sales from China to Japan amounted to only JPY 24.3 billion ( $\$ 0.22$ billion). ${ }^{10}$ This means that Japan realizes a significant economic advantage from its e-commerce trade surpluses.

\section{The Growth in Transaction Problems}

As Japan's e-commerce market has expanded, both domestically and internationally, the number of problem transactions has also grown. In 2017, the National Consumer Affairs Center (NCAC), an independent administrative agency established under both the Basic Consumer Act and the NCAC Act, received 77,318 complaints relating to consumer e-commerce purchases, which is more than double the number of complaints received in 2012 (31,934 cases).$^{11}$ These reports, covering both online direct sales and online auctions, typically focus on nondelivery, product defects or non-payment.

According to a survey asking people the reasons why they do not use homesharing services (like Airbnb) or ride sharing services (like Uber), more than $50 \%$ of Japanese consumers answered that they are concerned about how effectively any problems they experience will be addressed. Interestingly enough, even though consumers expect the quality of services delivered in Japan to be high, the consumers' concern about possible disputes is much higher than in the United States, United Kingdom, Germany and China, where the same question indicated that only around $30 \%$ of consumers indicated that they are concerned. ${ }^{12}$ This

12 Information Economy Division, METI, '2016 Establishing a Base for Data-Driven Society in Japan (Market Research for E-Commerce)', METI Report 2016, 2017, p. 71. Multiple answers were allowed for this survey. 
result indicates that potential transaction problems are more stressful for Japanese consumers, as well as how the current redress options available are not adequate to put their concerns at ease. Based on this data, an interim report published by the Review Conference of Sharing Economy (an expert council established under the Japanese Cabinet Secretariat) recommended strongly that businesses take proactive measures to put redress processes in place that will mitigate consumer anxiety around sharing economy transactions. ${ }^{13}$

\section{Existing Redress Options in Japan}

Despite the increasing volume of complaints, and strong consumer concern around potential transaction problems, to date, there have not been enough avenues for effective redress for Japanese consumers. While several options do exist, none are a good fit with e-commerce transactions. The primary paths available to Japanese consumers include the following:

Under the current Japanese court rule, parties can bring a claim for any amount less than JPY $600,000(\$ 5,455)$, which covers e-commerce disputes, to the Small Claims Trial (SCT) established as part of the local summary courts. ${ }^{14}$ Oral arguments within the SCT finish in just one day, and the judgement is delivered immediately after completion of the oral argument. ${ }^{15}$ The whole process takes around 2 months from the filing of the case to the final judgement. In order to make SCT navigable by parties without representation, the court provides a wide variety of guides and forms to demystify the procedure.

However, the filing cost makes SCT an inconvenient redress path for most online transactions. The cost to file a case is around JPY 4,000 (\$36.4), which is almost half of the value of an average e-commerce purchase. In addition, even though guides and forms are available, the complainant usually has to prepare a written petition and submit evidence (in addition to other administrative documents), which usually means that the complainant is going to have to get at least some advice from the court or a lawyer. In addition, the procedure is conducted entirely offline, meaning that the parties must attend the oral argument held in the court. ${ }^{16}$ In some cases, upon the defendant's request, the case will be transferred to the normal court, which means the complainant is always at risk that he or she will be pulled into a costly and time-consuming process. In fact, there were only 11,030 cases concluded in SCT in 2016, which comprises only $1.3 \%$ of the cases completed in the normal summary courts. ${ }^{17}$

17 Justice Statistics 2015, available at: www.courts.go.jp/app/files/toukei/179/009179.pdf. 
As to cross-border transactions, Code of Civil Procedure was amended in 2012 to admit the jurisdiction of the Japanese court for disputes filed by a consumer against foreign business as long as the consumer is a resident of Japan. ${ }^{18}$ However, even if the judgement is made for the consumer complainant, it is nearly impossible to enforce the judgement unless the business defendant owns assets in Japan, which means the consumer really is back at square one.

b Consumer ADR

In contrast to the options available through the courts, the most common alternative redress process for online consumers would be the NCAC. As described earlier, the NCAC deals with more than 75,000 consultations per year regarding online purchases. NCAC provides consumers information and advice, and in some cases, encourages and supports direct negotiations between the parties, which resolves $6 \%$ of the reported cases. ${ }^{19}$ However, since the advice and negotiation support is not binding on the parties, NCAC's processes are effective only when both parties are cooperative. If the seller does not respond to a contact from NCAC, or if the seller is unhappy with the recommended solution, the seller can just ignore the process and the NCAC cannot take any further action. Also, the NCAC only supports transactions between businesses and consumers, so its services are not helpful in $\mathrm{C} 2 \mathrm{C}$ or sharing economy transactions.

Now if the case is categorized as an 'important consumer dispute,' the consumer can file the case into the more formal dispute resolution mechanism operated by NCAC, which includes both mediation and arbitration. ${ }^{20}$ This process is handled by neutrals and case managers with extensive expertise in resolving consumer disputes. The process is provided free of charge, and it is expected to take about 4 months from filing to case resolution. The problem with this mechanism is that it is available only when a case is deemed an 'important consumer dispute,' which involves transactions that affect larger groups of consumers (e.g., mass claims) or transactions that have caused or will cause material damages to individuals. Therefore, ordinary ecommerce problems like item non-receipt or item not-as-described are unlikely to meet these requirements. In addition, like the negotiation support we outlined earlier, this more formal dispute settlement system still requires the counterparty's consent, because the NCAC has no enforcement power. The NCAC Settlement Committee does have the right to disclose the name of the seller if the seller does not cooperate with the suggested settlement, or if the seller has a pattern of similar disputes with buyers, but that disclosure is rarely enough to enforce the outcomes achieved. ${ }^{21}$ Perhaps due to this limited authority, in 2017, only 172 cases were referred to this 'important consumer

19 Consumer Affairs Agency, 'Report about implementation of consumer protection policy', 2015, p. 12. Available at: www.caa.go.jp/policies/policy/consumer_research/white_paper/pdf/ 28hakusho_summary.pdf.

21 Art. 36, NCAC Act. Art. 52, Para. 3, Operational Rules for NCAC Dispute Resolution Committee. 
dispute' process, which is a tiny percentage of the overall volume of likely ecommerce transaction problems experienced by consumers in Japan. ${ }^{22}$

NCAC has a branch that deals with cross-border transactions called the CCJ (which stands for Cross-border Consumer Centre Japan). The function of the CCJ is to receive complaints from Japanese consumers, translate them appropriately and work with the appropriate foreign organization to communicate with the foreign seller. The CCJ has established partnerships with 11 official foreign organizations, including the United States, Taiwan, Singapore, Vietnam, Thailand, Spain, Russia, Korea, Middle and South America, the Philippines and Malaysia. It handled 4,380 cases in 2016. ${ }^{23}$ The limitation of CCJ is, as with the domestic NCAC process, that it cannot resolve consumer disputes without the cooperation of the responding party. As a result, only $13 \%$ of the cases reported to CCJ are finally resolved. ${ }^{24}$

c Consumer's Self-Redress

Like many other jurisdictions around the world, Japanese law has a cooling-off period within which consumers may cancel a purchase, return goods and obtain a full refund for any reason. This period extends for 8 days from the time of delivery of the item purchased. However, online sellers can be exempted from this rule as long as they disclaim the cooling-off period in their initial advertisement. ${ }^{25}$ For example, Amazon.jp declares that the customer can get a full refund only if the delivered goods were unopened and unused; once an item is opened, the consumer can receive a refund of only $50 \%$ of the price paid. ${ }^{26}$ Likewise, most online sellers in Japan disclaim the cooling-off rule and implement their own refund policies, which limits its ability to protect consumers.

Another possible recourse for Japanese consumers is credit card chargebacks. Under this process, consumers can contact their credit card issuer to reverse the charge on a problem transaction. However, in Japan, the acceptable reasons for filing chargeback are limited to some specific circumstances, such as (i) the purchase was never made, (ii) the purchase was made but the item was not received, (iii) the purchase was made with a stolen or unauthorized credit care, (iv) the seller made an error in the purchase or (v) the seller never had authority to complete the purchase. Therefore, credit card chargebacks are difficult if not impossible to use in cases of item quality disputes or delays in delivery. ${ }^{27}$

As a matter of fact, the vast majority of online disputes in Japan are currently resolved through direct communication between consumers and mer-

NCAC website, www.kokusen.go.jp/adr/hunsou/hunsou.html.

23 Consumer Affairs Agency, 'Consumer White Paper', 2017, 1-1-3-(2), available at: www.caa.go.jp/ policies/policy/consumer_research/white_paper/2017/white_paper_109.html.

24 T. Matsumoto, 'Achievements and Challenges about CCJ', 2016, p. 19.

25 Art. 15-2, Act on Specified Commercial Transactions.

26 Amazon.jp website, https://www.amazon.co.jp/gp/help/customer/display.html/ref=hp_left_v4_ sib?ie=UTF8\&nodeId $=202063080 \&$ language $=$ en_US.

27 Y. Sekizaki, 'Credit Card Chargeback', 2015, p. 2, available at: http://myspace.private.coocan.jp/ odr/2015/2015_12.pdf. 
chants. In the case of B2C transactions, professional sellers are likely to make concessions in order to maintain good relationships with their customer base and to preserve a trustworthy reputation. However, if professional sellers refuse to compromise, or simply ignore the buyer complaint, usually the consumers will just give up their claim since they do not have an economically reasonable path to resolve the problem. In fact, a survey shows that $33 \%$ of domestic e-commerce consumer disputes were not resolved and $12 \%$ were resolved in a way unsatisfactory to the consumer. ${ }^{28}$ And in the case of C2C transactions, sellers tend to be even less motivated to be responsive, because it is unlikely that they will have a continuing relationship with the buyer. Rather, C2C sellers simply want to collect the payment as soon as possible and then have nothing to do with the buyer beyond that.

These challenges exist for domestic e-commerce transactions, where the buyer and the seller both reside in Japan. Throw in the confusion of crossborder transactions and you can see how the problems become even more daunting. Not only are there jurisdictional complexities and contradictions, there are also language differences and enforcement challenges. In practice, it is hard for any consumer, domestic or international, to get access to justice unless the seller is cooperative. If the seller decides not to participate, there are almost no current options in Japan to compel them to do so.

As we discussed previously, B2C and C2C e-commerce has become a significant part of the overall Japanese economy, and its importance will only grow as e-commerce volumes continue to rise. Since the current redress options are not effectively resolving these low-value, high-volume and frequently cross-border disputes, lack of redress will act as a brake on the expansion of e-commerce in Japan, and consumers will be inclined to spend their dollars elsewhere. To hold on to Japan's lead in e-commerce, and to encourage Japanese e-commerce to grow, Japan needs to make the deployment of ODR a priority, because ODR provides the redress options which meet the needs of consumers in this new digital economy.

\section{The History of ODR in Japan}

For the past two decades, several Japanese public organizations and industrial groups have tried to implement ODR to address e-commerce disputes. However, to date, none of those initiatives have become a sustainable and scaled option for consumer redress. The most prominent of these efforts include the following:

1 The ECOM Online Shopping Consultation Center

The ECOM (Electronic Commerce Promotion Council of Japan) was an organization composed of EC-related business entities, established in 2001 and disbanded in 2010. As a government-commissioned project, from 2003 
to 2006, the ECOM Online Shopping Consultation Center (OSCC) ran a demonstration project providing online $\mathrm{ADR}$, which offered advice for consumers, promoted negotiation between parties and conducted mediation online. The project was funded by government agencies (primarily the Ministry of Economy, Trade and Industry) and consumers could access all the services provided at no cost. ${ }^{29}$

The main challenge with this process, similar to the NCAC described earlier, was that the OSCC did not have authority to compel the respondent (usually the seller) to participate in negotiation or mediation. Also, the mediation provided through ECOM was too costly: at the beginning of the project, three expert mediators held a meeting for each case to draft mediation plan (later, it was amended to allow one mediator to handle one case). As a result, only $8.5 \%$ of the cases reached negotiation and $0.5 \%$ of cases went to mediation. ${ }^{30}$

On the other hand, the online advice that was provided in these cases was evaluated positively by nearly $80 \%$ of consumers. ${ }^{31}$ As an outcome of the 3 years' consultation, ECOM published the Online Consultation and Dispute Resolution Manual, which covers not only relevant regulations but also ethics, attitudes and techniques for consultants. ${ }^{32}$

It has been more than 10 years since the OSCC's online ADR experiment terminated, but the know-how of online consultations accumulated during the 3 years still provide very valuable lessons for us to design and implement new ODR processes that fit well with the Japanese e-commerce marketplace.

2 Shirogane-Cyberpol

At about the same time as the experiment of OSCC, in 2003, a non-profit organization named Shirogane-Cyberpol conducted an online ADR experiment for online auction disputes for 2 months (SOMPro: Shirogane-Cyberpol Online Mediation Project). ${ }^{33}$ Once SOMPro received a complaint, it contacted the counterparty and confirmed its willingness to join a negotiation. If the counterparty agreed, a lawyer designated by SOMPro supported the negotiation. The lawyer's work was provided to the parties free of charge (largely because the lawyer performed it as a volunteer).

One of the unique aspects of this project is that it coordinated with the largest auction platform in Japan (Yahoo! Auctions) to make it possible for the parties to erase any review posted on the site as part of the settlement agreement. This arrangement provided a strong incentive for the seller to participate in the negotiation, because sellers were well aware of the negative

METI, 'ECOM's Practical Experiment of ADR with respect to BtoC eCommerce', available at: www.meti.go.jp/policy/economy/consumer/consumer/tyui/pdf/shiryou7_adrgaiyou.pdf.

30 ECOM, 'Report on Demonstration of Internet-Related ADR', ECOM Report, 2005, p. 32, available at: www.jipdec.or.jp/archives/publications/J0004243.

31 Y. Harada, 'Experience from ECOM Online Shopping Consultation Center', 2016, p. 5, available at: http://myspace.private.coocan.jp/odr/2015/2015_09.pdf.

32 www.jipdec.or.jp/archives/publications/J0004244.

33 Y. Machimura, 'Report for the Result of Online ADR Experiment', 2003. Available at: http:// myspace.private.coocan.jp/odr/2015/2015_11.pdf. 
impact such bad reviews could have on the continued success of their online businesses.

Among the 36 cases filed to SOMPro over the 2-month experiment, seven cases proceeded to the supported negotiation phase and six reached final resolution. The average period for reaching an agreement was 46.6 days per case with 95 emails exchanged. In the final report of this pilot project, Prof Machimura pointed out that the main challenges in providing the type of ODR the project envisioned are the costs, financing, automation and data security. ${ }^{34}$

3 Challenges in Expanding ODR

Unfortunately, these demonstration projects in the early 2000s did not lead to the actual implementation of ODR in practice. One of the reasons for the failure of these efforts was that it was difficult to get parties to agree to participate in the negotiation. Since the ODR mechanisms utilized were not binding for parties, and there was no enforcement power, the respondent (often the seller) did not have enough incentive to join the negotiation. In fact, the number of respondents who actually took part in negotiation was less than $20 \%$ in both pilots. Second, the cost per case was too high to make the system financially sustainable. Even though the online process was less expensive than face-to-face ADR, there was still large of cost for the human consultants and mediators who actually gave advice or handled each case.

In the past experiments, technology was used merely as a communication tool, substituting for mail or telephone. Therefore, ODR could not fundamentally solve the problems that existed in offline ADR, typically, lack of incentive for participation and prohibitive costs.

However, things have changed in these 10 years. Now that online transactions are much more commonplace, it is more important for both business and consumers to have fast and fair redress for online disputes. We now have new mechanisms to incentivize sellers to join negotiation, such as the threat of credit card chargebacks and the even greater resonance of consumer evaluations. Also, ODR technology has improved to the point where the per case cost is much lower. It is no longer true that the cost increases at the same rate as dispute volumes. By leveraging data analysis, business rules and algorithmic resolutions, we can reduce the cost per dispute as the number of cases goes up.

\section{Practical Considerations in Developing ODR for Japanese e-Commerce}

Promoting the development of ODR in Japan requires us to first answer a central question: Who will develop and host the system? Courts would play this role, but the courts do not have a very strong track record when it comes to innovation and legislative reforms. Members of the judiciary are usually much more conser- 
vative in their management style, which contrasts with the rapid pace of innovation required for effective technology projects like ODR deployment.

Another possibility is government agencies. Japan Consumer Network has suggested that the Consumer Affairs Agency or the Ministry of Economy, Trade and Industry could establish an expert committee to discuss system development of ODR. ${ }^{35}$ This blueprint mirrors the approach that has been taken in the EU, which is government led with private sector participation. This approach would be particularly effective for implementation of ODR in NCAC or other public ADR institutions.

The third approach would be initiative by the private sector, specifically the online business merchants or the marketplace administrators, as a part of their services to their customer base. These private parties can best develop ODR systems that are fully integrated into their own businesses. If the government creates economic incentives for these private actors, it could spur the creation of ODR systems. However, there are always concerns about independence, impartiality and compliance when private actors retain control of ODR systems. Japan's Lawyer Act prohibits non-lawyers from delivering legal services for profit, with the specific exception of judicial scriveners in the case of small amount claims (equal to or less than JPY 1.4 million (approximately $\$ 12,727$ )) or Certified Dispute Settlement Services, ${ }^{36}$ so there is some precedent for private ODR systems to be granted a similar exception.

If ODR systems are designed and deployed by customer service teams within private merchants or marketplaces, regulations could require that mediations are conducted by an independent lawyer, judicial scrivener or panellist drawn from a limited number of Certified Dispute Settlement Services. But what about negotiation services? Could a marketplace administrator use ODR to support negotiation between the seller and the buyer by encouraging communication and providing information about its policies? Those kinds of services do not require participation from an outside ADR panel or non-profit. Presently, it is not clear whether such a service would fall within the 'reconciliation for the purpose of gaining reward' prohibition inside the Lawyer Act, but if the marketplace does not render a decision regarding the dispute, and it does not directly profit from the resolution process, it is not likely to be regarded as a breach of the Lawyer Act.

\subsection{Encouraging Parties to Participate}

One of the most difficult challenges in building ODR systems is appropriately incentivizing respondents to participate. In most private disputes these is no way to force the respondent to take part in the process short of going to court. Some online marketplaces can compel respondent participation by threatening account suspension or financial penalties, but short of that enforcement power, many respondents elect not to respond to new disputes because all of the possible outcomes are negative from their perspective.

36 Art. 72 of Lawyer Act, Art. 3, Para. 1, Item 7 of Judicial Scrivener Act, Arts. 5, 6 of Act on Promotion of Use of Alternative Dispute Resolution. 
A possible solution to this challenge would be to establish a new regulation that requires that all consumers have easy access to ODR, and that merchants would be required to participate in the process. However, it is difficult to convince legislators to pass such a regulation without successful ODR systems already in place, and a record of successful resolutions. It is possible to promote ODR solely through voluntary implementations by merchants or marketplace administrators. But past efforts along those lines have achieved only spotty compliance, with huge variation in ODR quality. In order to motivate private sector actors to implement ODR in their own platform, there needs to be a compelling economic rationale.

Large-scale studies of the ODR processes at eBay have demonstrated that there is a strong economic rationale for businesses to invest in redress systems. Data drawn from the eBay data warehouse indicates that businesses that provide fast and fair ODR resolutions enjoy significantly higher buyer loyalty and consumer reactivation rates, which can generate significant boosts in profits. According to the study conducted by eBay, consumers who reported a transaction problem and achieved a resolution through mutual agreement with their seller increased their activity on eBay at an average of $15 \%$ in the 6 months following the disagreement. Also surprising was the finding that consumers who filed a dispute had higher loyalty on average than consumers who did not file a dispute, regardless of its outcome (i.e., no matter whether the buyer 'won' and got a refund or 'lost' and did not get a refund). ${ }^{37}$ This result demonstrates that fast and fair redress is a core component of user trust, and that businesses who implement ODR will enjoy a sustainable competitive advantage over their competitors who do not make similar investments.

This advantage would be especially significant in the Japanese market, since consumers in Japan have indicated that they are more concerned about potential purchase problems than consumers in other countries (as explained earlier). Therefore, private merchants and marketplaces in Japan, regardless of the kinds of transactions they host, have a strong financial incentive to develop and deploy ODR systems independent of any regulatory or legal pressure.

\subsection{Enforcing ODR Outcomes}

The number one determinant of a successful ODR program is enforceability. If the resolution achieved within an ODR process is not enforceable, the consumer will be frustrated, because the outcome they achieved is highly unlikely to become a reality. In ODR processes where agreements are achieved by mutual agreement, enforcement is less of an issue, because there is a high degree of compliance with resolutions agreed to by both parties. But the lack of enforcement becomes a major challenge in ODR processes where the parties could not reach agreement, so the matter is decided by a third-party neutral.

Could the parties agree in an initial purchase agreement (usually, terms and conditions prepared by the seller or the platform and agreed to by the consumer) 
that the outcome of any eventual ODR negotiation or mediation is legally enforceable? These pre-dispute binding resolution agreements are becoming more popular in the United States, but Japanese law does not allow settlements or mediation agreements made outside the court to be enforceable. ${ }^{38}$ Likewise, an agreement to go to binding arbitration will not work since the Japanese Arbitration Act allows consumers to unilaterally cancel arbitration clauses in their consumer contracts. As a result, private merchants usually have no motivation to embed arbitration clauses in their customer agreements.

There are several options for enforcement of ODR outcomes in Japan. The first is de facto enforceability, sometimes described as chargeback and escrow. De facto enforceability gives the consumer power to compel merchant enforcement. The simplest example of this kind of enforcement is credit card chargebacks. Consumers can file a chargeback for any payment made on their credit card just by calling their card issuer and filing a chargeback. Merchants cannot block the chargeback from being filed, though they can 're-present' the charge if they feel the chargeback was inappropriate. ODR processes do not infringe on consumer chargeback rights, but merchants are likely to prefer ODR because they enable the possibility of a resolution by mutual agreement, which the chargeback process does not account for.

If the marketplace administrator has an escrow function (i.e., the buyer deposits the purchase amount in the escrow account of the marketplace and releases it only when he or she has confirmed delivery of the ordered goods and acceptable quality), this de facto enforcement is even more flexible. The consumer is never out of control, even after he or she has sent the money, because the merchant does not receive payment until the consumer has indicated that he or she is fully satisfied with the transaction. Most of the time the escrow process will work without external intervention, but if a dispute does arise, then a third-party mediator or arbitrator can decide the appropriate outcome and then the marketplace can move the funds held in escrow as the outcome requires. This approach makes ODR outcomes de facto enforceable even without a legal agreement between the parties.

As an example, suppose that in a case of delayed delivery, the buyer and seller cannot agree about appropriate compensation, so the arbitrator decides that the seller should give the buyer a $30 \%$ refund on the original purchase price. After receiving the decision from the arbitrator, the marketplace administrator could pay $70 \%$ of the buyer's payment from the escrow account to the merchant and refund the remaining $30 \%$ to the buyer. The escrow functionality enables the ODR process to have de facto enforceability even after the payment is done, even if the respondent (the merchant) disagrees with the arbitrator's decision.

\subsection{ODR and Reputation Systems}

In addition to this de facto enforceability, there are other possible tools to encourage parties to comply with outcomes delivered by the ODR system. For example, buyers can be given the ability to publicly review the performance of their sellers. 
These reviews are critical for the seller's reputation within a particular marketplace, because if future potential buyers read critical reviews of a particular seller, they will be less likely to purchase items from that seller. Therefore, sellers are strongly motivated to comply with ODR outcomes in order to protect their public reputation. Furthermore, as was the case in the Shirogane-Cyberpol experiment, if the system allows merchants to erase bad reviews as part of their compliance with an ODR process, the sellers will be strongly motivated to use and comply with ODR outcomes.

\subsection{Funding ODR Systems}

A final concern is the funding and sustainability of ODR programmes. One of the reasons why consumers do not pursue redress through the courts for their e-commerce problems is the challenge of cost. No one wants to spend $\$ 100$ on a lawyer to resolve a $\$ 50$ dispute. As a result, ODR systems need to be as inexpensive as possible, especially if they are going to process low-value cases. Automation and algorithmic resolutions within ODR processes can improve the efficiency and expense per case, which can improve this cost curve.

In fact, ODR can dramatically reduce cost for customer service. Using the power of software algorithms within its ODR platform, eBay succeeded in resolving $90 \%$ of disputes without human intervention from an eBay employee. Likewise, ODR mechanisms at PayPal saved the company more than $\$ 7.5$ million in customer service headcount costs in the first year alone, and each year after that the savings compounded. ${ }^{39}$ These savings improve the cost leverage for ODR, which makes the expense per case manageable.

Each ODR deployment should go through a cost-benefit analysis to ensure that the amount expended in building the system is less than the economic benefit of the system once it comes live. Automation to reduce the cost per case combined with increases in customer loyalty and retention should improve leverage to the point where any private entity would quickly realize that ODR investments more than pay for themselves in a short period of time. Add in the government's interest in providing fast and fair redress to citizens, and the business case for ODR becomes quite strong.

\subsection{Neutrals}

The final question regarding ODR focuses on the neutrals who will be providing services within the ODR process. In Japan, the mediator should probably be an attorney or a judicial scrivener qualified within that country itself. The reason for this limitation is not only to assure consistent quality of mediation services, but also to comply with Japanese laws. As described previously, Japan's Lawyer Act allows only legal experts (lawyers or judicial scriveners) or Certified Dispute Settlement Service to deal with reconciliation for the purpose of gaining reward. In order to comply with these regulations, Japanese ODR systems should probably select their neutrals from these approved panels. 
The problem with this relatively limited pool of neutrals is that these neutrals are usually quite expensive. But the challenge of this expense is minimized by three factors:

- First, because only a small percentage of cases generate a dispute, and only a small percentage of disputes go to mediation, the merchants or marketplace administrators have enough reason to bear the cost for these professionals.

- Second, working as a mediator in a simple e-commerce case is a good opportunity for customer service staff to engage in professional development. In fact, many individuals are willing to provide such services for free: in an open Q\&A service run by the biggest attorney-client matching service provider in Japan, Bengoshi.com, about 18,000 answers per month to legal questions were answered by attorneys for free. ${ }^{40}$ Managing online mediations could be a good opportunity for legal professionals to demonstrate their skill at providing legal advice, which can open professional doors. Considering this benefit, professionals will likely be willing to handle these online mediations for significantly lower fees.

- Third, if an ODR system partners with a Certified Dispute Settlement Service, non-certified panel members such as past NCAC consultants or students could also work as mediators. In general, such service providers are significantly cheaper than hiring legal experts at their stated hourly rates.

\section{Conclusion}

Access to justice is an essential and fundamental right. As our society moves online, we must ensure that citizens and consumers can get just resolutions to their online problems as easily as they can get justice offline. That is why developing and expanding ODR is essential for the expansion of e-commerce both within Japan and around the world. As e-commerce grows, government must invest in ODR so as to ensure continued and improving access to justice from customers. This is essential to maintain trust.

To date, this door has been closed to Japanese e-commerce consumers. Existing options do not provide adequate access to redress. The court process is too costly and time-consuming. Governmental ADR processes are not binding, making them largely ineffective. The scenarios in which cooling-off rights or credit card chargebacks can provide just resolutions are relatively limited. As a result, consumers do not reach a satisfactory settlement in nearly half of Japanese ecommerce cases. That is a problem.

In fact, Japan was a leader in experimenting with ODR in the early 2000s. Unfortunately, those experiments failed because of the expensive running cost and lack of enforcement power. However, by making use of modern innovations in ODR (including automation and algorithmic resolutions), and by encouraging merchants and marketplace providers to invest in ODR in order to make their business more efficient and profitable, Japan will be able to reclaim its leadership 
and develop sustainable ODR systems to support the continued growth of e-commerce.

Even though ODR is nascent in Japan, there is a huge potential. With just a little push, ODR can become a fundamental part of Japanese infrastructure in the near future. It is time for business, government, lawyers and consumers alike to work together to develop ODR in Japan to ensure better access to justice and to lay the groundwork for prosperity in the expanding online economy. 